\title{
Phylogenetic studies of Nocardia species based on gyrB gene analyses
}

\author{
Correspondence \\ Tohru Gonoi \\ gonoi@faculty.chiba-u.jp
}

Received 24 March 2009

Accepted 8 October 2009

\author{
Kenjiro Takeda, $¥$ Yingqian Kang, $† \S$ Katsukiyo Yazawa, Tohru Gonoi \\ and Yuzuru Mikami
}

Medical Mycology Research Center, Chiba University, 1-8-1 Inohana, Chuo-ku, Chiba 260-8673, Japan

\begin{abstract}
Phylogenetic analyses of 56 type species of Nocardia were conducted using the partial nucleotide sequences of the gyrase B-encoding gene $(g y r B)$. The interspecies similarities of the gyrB gene for the 56 type species were $82.4-99.9 \%$, which corresponded to $270-2 \mathrm{nt}$ differences in the partial gene sequences of approximately $1200 \mathrm{nt}$. In comparison with phylogenetic relationships, gyrB gene sequence information was generally consistent with that of 16S rRNA gene sequences with minor exceptions. However, the degree of divergence of the gyrB gene sequences was approximately 3.6 times greater than those of the 16S rRNA gene, suggesting a higher discriminative power of $g y r B$ sequence information compared with 16S rRNA gene sequences for Nocardia species. The Nocardia type species were clustered based on gyrB sequence similarity values of $93.5 \%$ and above. Among the 56 type species, 38 were distributed in 13 clusters, each comprising 2 to 7 species. The remaining 18 species were classified into an independent cluster, in which the similarity between each species and the other 55 Nocardia species was less than $93.5 \%$. Among the eight mycolic acid-containing actinomycete genera in the suborder Corynebacterineae, Nocardia was clearly differentiated from the other genera, such as Rhodococcus, by gyrB gene analyses (similarity values of gyrB sequences for Nocardia and Rhodococcus were $75-85 \%$ ), indicating that the gyrB gene is a useful alternative to the $16 \mathrm{~S}$ rRNA gene for the determination of phylogenetic relationships between the genus Nocardia and the seven other actinomycete genera.
\end{abstract}

\section{INTRODUCTION}

Members of the genus Nocardia are ubiquitous in the environment. They can be found worldwide as saprophytic components in fresh and salt water, soil, dust, decaying vegetation and decaying faecal deposits from animals (Brown-Elliott et al., 2006). Most Nocardia species can cause infections in both immunocompetent and immunocompromised patients (Conville et al., 2004). Infection has been considered to occur by inhalation from environmental sources, mainly soil; pulmonary disease is therefore the most common clinical form. The recent increase in immunocompromised patients has led to soaring numbers of nocardiosis patients (Kageyama et al., 2004a, b; Poonwan et al., 2005). Reportedly, Nocardia

†These authors contributed equally to this work.

łPresent address: Nittetsu Hitachi Systems Engineering Inc., Chuo-ku, Akashi-cho, Tokyo 104-6591, Japan.

§Present address: Department of Microbiology, Guiyang Medical University, Guizhou Province 550004, Republic of China.

The GenBank/EMBL/DDBJ accession numbers for the Nocardia gyrB gene sequences reported in this paper are AB447397-AB447401, AB450768-AB450779 and AB450782-AB450820. species show a species-specific drug susceptibility pattern (Ishikawa et al., 2004; Yazawa et al., 1993). Therefore, early species determination is necessary to start the correct drug therapy.

Nocardia species are currently being characterized extensively by molecular analysis, in addition to chemical and biochemical analysis (Chun \& Goodfellow, 1995; Hoshino et al., 2007). The sequence of the 16S rRNA gene has been widely used as a molecular marker to estimate relationships in bacterial phylogeny (Goodfellow, 1998). However, the $16 \mathrm{~S}$ rRNA gene has a low mutation rate in evolution, which occasionally makes discrimination between closely related species, such as Nocardia abscessus and those in the Nocardia nova complex, difficult (Conville et al., 2004).

The gyrase B-encoding gene $(g y r B)$, which encodes the $\beta$ subunit of DNA gyrase, a type II DNA topoisomerase, is present universally among Gram-positive and Gramnegative bacteria. Yamamoto \& Harayama (1995) used the $g y r B$ gene in the taxonomic classification of Pseudomonas putida and found that gyrB gene sequence information was more useful than that of the 16S rRNA gene because the base substitution frequency of the gyrB gene was much higher than that of the $16 \mathrm{~S}$ rRNA gene. 
Table 1. Source of Nocardia type species and R. koreensis, and GenBank accession numbers for their gyrB gene sequences

R. koreensis was used as an outgroup in the neighbour-joining analysis.

\begin{tabular}{|c|c|c|}
\hline Species & Strain no. & $\begin{array}{c}\text { GenBank } \\
\text { accession no. }\end{array}$ \\
\hline N. abscessus & IFM 10029 & AB447398 \\
\hline N. africana & IFM 10147 & AB447399 \\
\hline N. alba & IFM 10588 & AB453918 \\
\hline N. anaemiae & IFM 0323 & $\mathrm{AB} 447400$ \\
\hline N. aobensis & IFM 0372 & $\mathrm{AB} 447401$ \\
\hline N. araoensis & IFM 0575 & $\mathrm{AB} 450768$ \\
\hline N. arthritidis & IFM 10035 & AB450769 \\
\hline N. asiatica & IFM 0245 & $\mathrm{AB} 450770$ \\
\hline N. asteroides & IFM 0319 & $\mathrm{AB} 450771$ \\
\hline N. beijingensis & IFM 10174 & $\mathrm{AB} 450772$ \\
\hline N. brasiliensis & IFM 0236 & $\mathrm{AB} 450773$ \\
\hline N. brevicatena & IFM 0283 & $\mathrm{AB} 450774$ \\
\hline N. caishijiensis & IFM 10344 & $\mathrm{AB} 450775$ \\
\hline N. carnea & IFM 0237 & $\mathrm{AB} 450782$ \\
\hline N. cerradoensis & IFM 10366 & $\mathrm{AB} 450777$ \\
\hline N. concava & IFM 0354 & AB450778 \\
\hline N. crassostreae & IFM 10173 & AB450779 \\
\hline N. cummidelens & IFM 10176 & $\mathrm{AB} 450783$ \\
\hline N. cyriacigeorgica & IFM 10235 & $\mathrm{AB} 450784$ \\
\hline N. elegans & IFM 10589 & $\mathrm{AB} 450785$ \\
\hline N. exalbida & IFM 0803 & AB447397 \\
\hline N. farcinica & IFM 0284 & AB014169 \\
\hline N. flavourosea & IFM 0851 & $\mathrm{AB} 450787$ \\
\hline N. fluminea & IFM 10138 & AB450788 \\
\hline N. higoensis & IFM 10084 & AB450789 \\
\hline N. ignorata & IFM 10475 & $\mathrm{AB} 450790$ \\
\hline N. inohanensis & IFM 0092 & $\mathrm{AB} 450791$ \\
\hline N. jiangxiensis & IFM 10633 & AB450792 \\
\hline N. kruczakiae & IFM 10565 & AB450793 \\
\hline N. miyunensis & IFM 10632 & AB450794 \\
\hline N. neocaledoniensis & IFM 10560 & AB450795 \\
\hline N. niigatensis & IFM 0833 & AB450796 \\
\hline N. nova & IFM 0290 & $\mathrm{AB} 450797$ \\
\hline N. otitidiscaviarum & IFM 0239 & AB450798 \\
\hline N. paucivorans & IFM 10001 & AB450799 \\
\hline N. pigrifrangens & IFM 10533 & $\mathrm{AB} 450800$ \\
\hline N. pneumoniae & IFM 0784 & $\mathrm{AB} 450801$ \\
\hline N. pseudobrasiliensis & IFM 0624 & $\mathrm{AB} 450802$ \\
\hline N. pseudovaccinii & IFM 10376 & $\mathrm{AB} 450803$ \\
\hline N. puris & IFM 10564 & $\mathrm{AB} 450804$ \\
\hline N. salmonicida & IFM 0849 & AB450820 \\
\hline N. seriolae & IFM 0286 & $\mathrm{AB} 450805$ \\
\hline N. shimofusensis & IFM 10331 & AB450806 \\
\hline N. sienata & IFM 10088 & $\mathrm{AB} 450807$ \\
\hline N. soli & IFM 10177 & AB450808 \\
\hline N. takedensis & IFM 10572 & AB450809 \\
\hline N. testacea & IFM 0937 & AB450810 \\
\hline N. thailandica & IFM 10145 & AB450811 \\
\hline N. transvalensis & IFM 0333 & $\mathrm{AB} 450812$ \\
\hline N. uniformis & IFM 0856 & $\mathrm{AB} 450813$ \\
\hline N. vaccinii & IFM 10284 & AB450814 \\
\hline
\end{tabular}

Table 1. cont.

\begin{tabular}{|llc|}
\hline Species & Strain no. & $\begin{array}{c}\text { GenBank } \\
\text { accession no. }\end{array}$ \\
\hline N. vermiculata & IFM 0391 & $\mathrm{AB} 450815$ \\
N. veterana & IFM 10086 & $\mathrm{AB} 450816$ \\
N. vinacea & IFM 10175 & $\mathrm{AB} 450817$ \\
N. xishanensis & IFM 10549 & $\mathrm{AB} 450818$ \\
N. yamanashiensis & IFM 0265 & $\mathrm{AB} 450819$ \\
R. koreensis & JCM 10743 & $\mathrm{AB} 450821$ \\
\hline
\end{tabular}

Recently, we also reported the usefulness of $\operatorname{gyrB}$ gene information for phylogenetic studies of Gordonia (Kang et al., 2009). In the present study, we analysed the phylogenetic relationship of 56 type species of Nocardia based on gyrB gene sequences and compared the results with those from the 16S rRNA gene.

\section{METHODS}

The bacterial strains used in this study are presented in Table 1. Type strains of each Nocardia species from the culture collection of the Medical Mycology Research Center, Chiba University, Japan [formerly the Research Center for Pathogenic Fungi and Microbial Toxicoses (IFM strains)] were used. They were cultured in MullerHinton II broth (Difco Laboratories) with $1 \%$ glucose and $1 \%$ glycerol at $30{ }^{\circ} \mathrm{C}$ for 1 week (Kageyama et al., 2005). The PCR amplification procedure for the gyrB gene for most Nocardia species was applied without a DNA extraction procedure. The preparation for direct PCR amplification was as follows: 1 PCR bead (Ready-To-

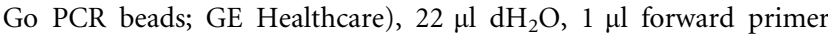
$(20 \mathrm{pM}), 1 \mu \mathrm{l}$ reverse primer $(20 \mathrm{pM})$ and $1 \mu \mathrm{l}$ diluted culture were added to each test tube for PCR amplification. Fresh cultures of all Nocardia strains in this study were diluted with $\mathrm{dH}_{2} \mathrm{O}$ at a concentration equal to a McFarland standard 4.0. However, when amplification was not successful, the DNA extraction was processed according to the instructions for the Isoplant II kit (Nippon Gene) for bacteria and yeast. Partial sequences of the gyrB gene were amplified using PCR with degenerate universal PCR primers, as described by Yamamoto \& Harayama (1995), with slight modifications. The modifications of primers were based on the genome sequences of Nocardia farcinica (Ishikawa et al., 2004). The primer sequences are presented in Table 2. The amplification reactions were performed under the following conditions: initial denaturation at $94{ }^{\circ} \mathrm{C}$ for $5 \mathrm{~min}$, followed by 30 cycles of denaturation at $95{ }^{\circ} \mathrm{C}$ for $1 \mathrm{~min}$, primer annealing at $55{ }^{\circ} \mathrm{C}$ for $1 \mathrm{~min}$ and extension at $72{ }^{\circ} \mathrm{C}$ for $1.5 \mathrm{~min}$, with a final extension at $72{ }^{\circ} \mathrm{C}$ for $10 \mathrm{~min}$.

The PCR products were purified using ExoSAP-IT (GE Healthcare). Cycle sequencing was performed using a BigDye terminator v1.1 cycle sequencing kit (PE Applied Biosystems), as described previously (Kageyama et al., 2004d). Determination of the nucleotide sequences for the PCR products was performed using an automated genetic analyser (ABI Prism 3100; PE Applied Biosystems).

The $\operatorname{gryB}$ gene sequences determined in this study and the 16S rRNA gene sequences obtained from GenBank were aligned using CLUSTAL W (Thompson et al., 1994). Nucleotide substitution rates ( $K_{\text {nuc }}$ values) were calculated (Kimura, 1980), and phylogenetic trees were constructed using the neighbour-joining method (Saitou \& Nei, 1987). Bootstrap values based on 1000 replications are listed as percentages at the branching points of the tree (Fig. 1). 
Table 2. Primers used for PCR amplification and sequencing of the gyrB gene

\begin{tabular}{|llc|}
\hline $\boldsymbol{g} \boldsymbol{y} \boldsymbol{r} \boldsymbol{B}$ primer & \multicolumn{1}{c|}{ Sequence $\left(\mathbf{5}^{\prime} \rightarrow \mathbf{3}^{\prime}\right)$} & Position (nt) \\
\hline F1 & GAGGTCGTCATGACCCAGCTGCACGCGGGCGGCAAGTTCG & $355-394^{*}$ \\
R1296 & GATGTGCTGGCCGTCGACGTCGGCGTCGGCCAT & $1651-1683^{*}$ \\
UP-1 & GAGGTCGTCATGACCCAGCTGCAYGCNGGNGGNAARTTYGA & $91-104 \dagger$ \\
UP-2r & AGCAGCGTCGAGATGTGCTGGCCRTCNACRGCNGCRTCNGTCAT & $495-509 \dagger$ \\
sF1 & GAGGTCGTCATGACCCAGCTGCA & $355-377^{*}$ \\
sF358 & CAGGAGATGGCGTTCCTGAACA & $649-670^{*}$ \\
sF609 & GTGCACACCTTCGCCAA & $964-980^{*}$ \\
sF799 & AGCCGCAGTTCGAGGGCCAGAC & $1154-1175^{*}$ \\
sR495 & CTTGGTCCGGTTGATGTG & $850-867^{*}$ \\
sR804 & GTCTTGGTCTGGCCCTCGAACTG & $1159-1181^{*}$ \\
sR1068 & GAGATCTACATCGTGGAG & $1423-1440^{*}$ \\
sR1296 & GATGTGCTGGCCGTCGACGTCGGCGTCGGCCAT & $1651-1683^{*}$ \\
\hline
\end{tabular}

${ }^{\star}$ Positions correspond to the gyrB nucleotide sequence of N. farcinica IFM 10152 (GenBank accession no. AP006618). $\dagger$ Positions correspond to the amino acid sequences of the subunit B protein of DNA gyrase from Escherichia coli K-12 (GYRB_ECOLI in the Swiss-Prot database).

\section{RESULTS AND DISCUSSION}

Cultures of Nocardia strains were subjected to PCR amplification of the $g y r B$ gene region using degenerate PCR primers. Among the 57 Nocardia species initially tested, the $g y r B$ genes of 56 species were amplified. The gyrB gene of Nocardia tenerifensis (IFM $10554^{\mathrm{T}}$ ) was not amplified appropriately with the primers used. Amplified PCR product sizes were approximately $1200 \mathrm{bp}$, similar to those of the known partial gyrB sequences of other bacteria. The GenBank accession numbers of the sequences obtained are shown in Table 1.

The interspecies similarity (percentage of identical nucleotides in the sequence) range of Nocardia gyrB gene sequences in this study was 82.4-99.9\%, corresponding to nucleotide differences of 270-2 nt. We also obtained $16 \mathrm{~S}$ rRNA gene sequences of the Nocardia species from GenBank and analysed them over a unified length (1350 bp). The interspecies similarity range of the $16 \mathrm{~S}$ rRNA sequences was $94.4-100.0 \%$, corresponding to nucleotide differences of 75-0 nt (Fig. 1a). These data indicated that the divergence degree of the $g y r B$ gene was approximately $3.6(270 / 75 \mathrm{bp})$ times greater than that of the $16 \mathrm{~S}$ rRNA gene.

The genus Nocardia belongs to the family Nocardiaceae, suborder Corynebacterineae. The suborder currently contains eight genera as the major mycolic acid-containing organisms: Dietzia, Gordonia, Mycobacterium, Nocardia, Rhodococcus, Skermania, Tsukamurella and Williamsia (Stackebrandt et al., 1997; McMinn et al., 2000). Table 3 shows the intergenus similarity ranges ( gyrB and 16S rRNA gene sequences) between the studied Nocardia species and the other seven mycolic acid-containing genera. For the gyrB gene sequences, the intergenus similarities between Nocardia and the other genera were $68.1-87.3 \%$, with a mean value of $76.1 \%$. For the $16 \mathrm{~S}$ rRNA gene sequences, the similarities were $88.9-97.2 \%$, with a mean value of $93.1 \%$. These data suggested that the discriminatory power of the $g y r B$ gene is approximately 3.8 times greater than that of the 16S rRNA gene for differentiating Nocardia species from other actinomycetes. From the study of gyrB gene sequences, it was also evident that the genus Nocardia is most closely related to the genus Rhodococcus, followed by Mycobacterium and Gordonia (Table 3). Because all of these mycolic acid-containing actinomycetes are mutually closely related, and because it is not easy to discriminate them by morphological and biochemical methods, the gyrB sequence information might help the development of a useful laboratory technique for identifying Nocardia and other organisms.

Phylogenetic trees based on gyrB and 16S rRNA gene sequences for the 56 type species of Nocardia studied were constructed using the neighbour-joining method with Rhodococcus koreensis as an outgroup (Fig. 1a, b). A similar phylogenetic tree was constructed with the amino acid sequences deduced from the gyrB genes (data not shown). Comparison of the phylogenetic trees based on the gyrB and 16S rRNA genes revealed that the two trees showed similar but not entirely identical phylogenetic relationships for the Nocardia species. However, most bootstrap values of the Nocardia species on the gyrB tree were significantly higher than those on the 16S rRNA gene tree.

Based on interspecies similarities of the $\operatorname{gyr} B$ gene sequences greater than $93.5 \%$, we grouped the 56 Nocardia type strains into a number of clusters (Table 4). The first 13 clusters were as follows: cluster 1, Nocardia africana, Nocardia aobensis, Nocardia cerradoensis, Nocardia elegans, Nocardia kruczakiae, N. nova and Nocardia veterana (similarities of 94.1-99.6\%); cluster 2, N. abscessus, Nocardia arthritidis, Nocardia asiatica, Nocardia exalbida and Nocardia pneumoniae (93.6$98.0 \%$ ); cluster 3, Nocardia alba, Nocardia cummidelens, 
(a) $\quad \frac{0.005}{K_{\text {nom }}}$

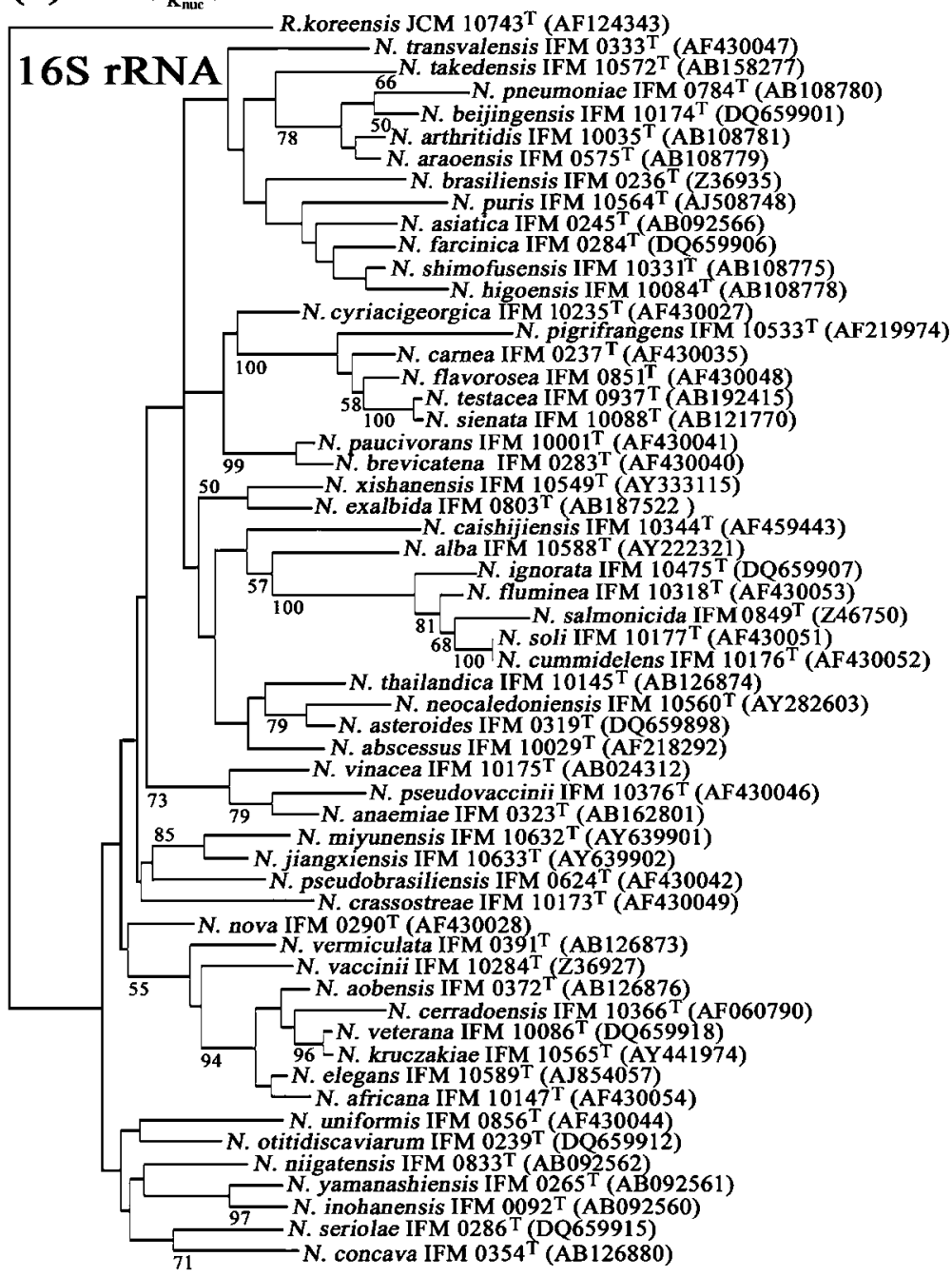

(b) $\left|\frac{0.02}{K_{\text {mex }}}\right|$

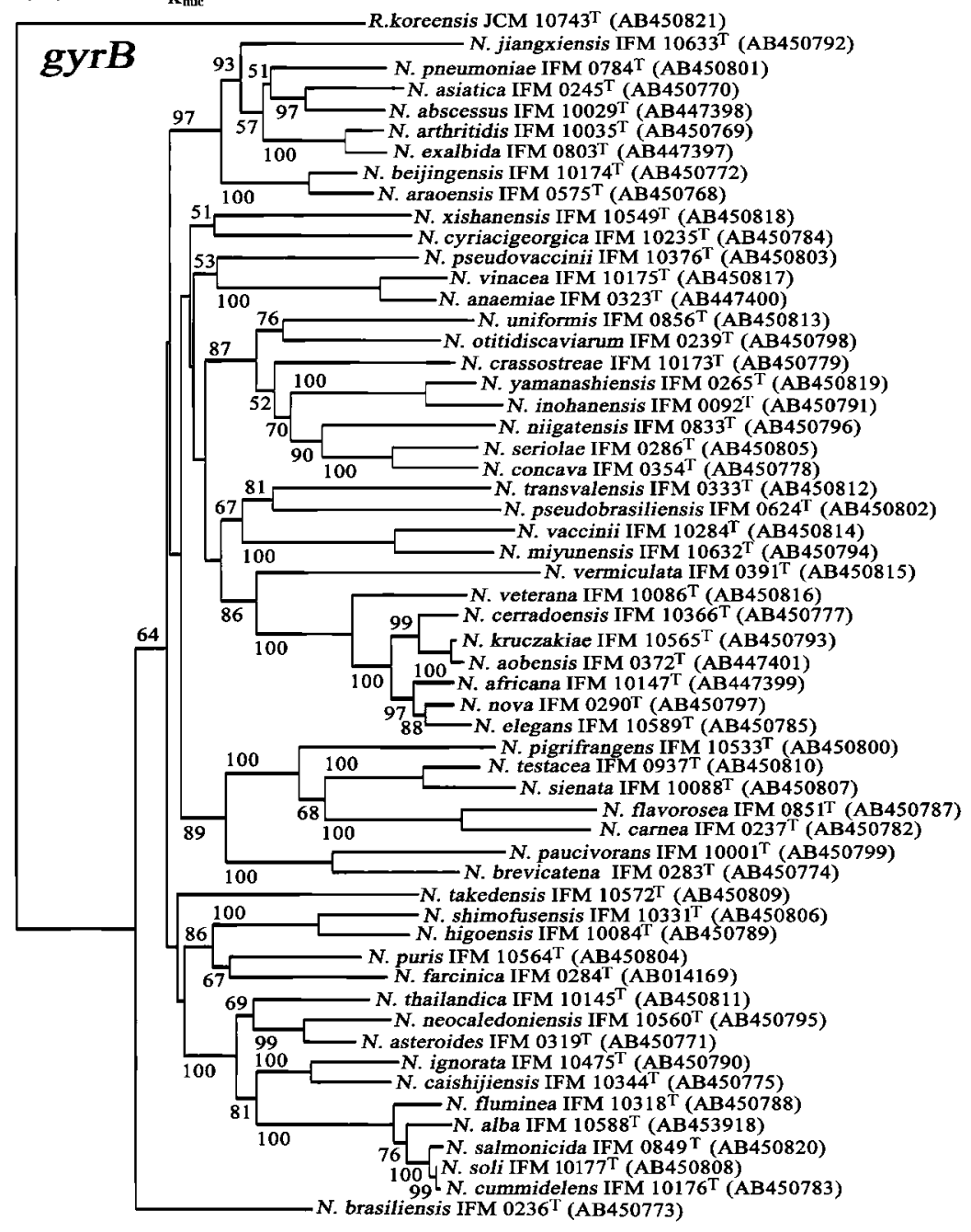

Fig. 1. Phylogenetic trees derived from the $16 \mathrm{~S}$ rRNA gene (a) and the gyrB gene (b) sequences of 56 type species of Nocardia. The trees were created using the neighbour-joining method. The respective $K_{\text {nuc }}$ values were 0.005 in (a) and 0.02 in (b). The numbers on the tree represent bootstrap values for the branch points. Bootstrap values greater than $50 \%$ significance are indicated. 
Table 3. Relative similarity values of the gyrB gene sequences of the seven other mycolic acid-containing actinomycete genera compared with Nocardia species

\begin{tabular}{|lcc|}
\hline Genus & gyrB (\%) & 16S rRNA (\%) \\
\hline Rhodococcus & $75.2-87.3$ & $92.4-97.2$ \\
Skermania & $73.8-79.8$ & $91.4-95.1$ \\
Tsukamurella & $73.9-80.5$ & $92.0-95.0$ \\
Gordonia & $72.8-82.5$ & $90.8-94.9$ \\
Mycobacterium & $75.5-82.0$ & $88.9-94.6$ \\
Dietzia & $68.1-73.3$ & $89.7-94.4$ \\
Williamsia & $68.5-73.0$ & $90.8-96.2$ \\
Range (minimum- & $68.1-87.3$ & $88.9-97.2$ \\
maximum) & & \\
Mean similarity* & 76.1 & 93.1 \\
\hline
\end{tabular}

${ }^{*}$ Mean similarities were estimated from the maximum and minimum values of each genus.

Nocardia fluminea, Nocardia soli and Nocardia salmonicida (97.1-99.4\%); cluster 4, Nocardia anaemiae and Nocardia vinacea (97.0\%); cluster 5, Nocardia araoensis and Nocardia beijingensis (97.1\%); cluster 6, Nocardia asteroides, Nocardia neocaledoniensis and Nocardia thailandica (93.6-96.7\%); cluster 7, Nocardia caishijiensis and Nocardia ignorata (97.9\%); cluster 8, Nocardia carnea and Nocardia flavorosea (93.7\%); cluster 9, Nocardia concava and Nocardia seriolae (95.5\%); cluster 10, Nocardia higoensis and Nocardia shimofusensis (95.2\%); cluster 11, Nocardia inohanensis and Nocardia yamanashiensis (96.9\%); cluster 12, Nocardia miyunensis and Nocardia vaccinii (94.7\%); cluster 13, Nocardia sienata and Nocardia testacea (96.3\%). The 13 clusters formed individual clades in the phylogenetic tree based on the gyrB sequences. There were 18 remaining Nocardia type species that had gyrB similarities less than $93.5 \%$ when compared with the remaining species. These 18 Nocardia type strains were only distantly related to the other species, indicating they could easily be discriminated based on their gene sequence information in a phylogenetic study. The results confirmed that $g y r B$ gene sequence information is useful for interspecies discrimination of Nocardia strains, as well as for intergenus discrimination.

High interspecies similarities of the $g y r B$ gene sequences were found among $N$. soli, N. cummidelens, N. fluminea, $N$. salmonicida and $N$. alba. The amino acid sequences deduced from the genes of the first four were identical, whilst the similarities of the $16 \mathrm{~S}$ rRNA gene sequences in the four species ranged from 97.5 to $99.1 \%$. According to a published study, however, the four species are distinguishable by, for example, different colony colours (Maldonado et al., 2000). In addition, the amino acid sequences deduced from the gyrB genes of $N$. aobensis and $N$. kruczakiae were identical. These organisms have similar phenotypes in several biochemical tests, but differ in their
Table 4. Grouping of the 56 type species of Nocardia based on gyrB gene sequence similarity values of $93.5 \%$ or above

Clusters numbered 14-31 comprised only one species because the similarity of their respective $g y r B$ sequences to the remaining Nocardia species was less than $93.5 \%$.

\begin{tabular}{|c|c|c|}
\hline Cluster no. & Species & Strain no. \\
\hline \multirow[t]{7}{*}{1} & N. africana & IFM 10147 \\
\hline & N. aobensis & IFM 0372 \\
\hline & N. cerradoensis & IFM 10366 \\
\hline & N. elegans & IFM 10589 \\
\hline & N. kruczakiae & IFM 10565 \\
\hline & N. nova & IFM 0290 \\
\hline & N. veterana & IFM 10086 \\
\hline \multirow[t]{5}{*}{2} & N. abscessus & IFM 10029 \\
\hline & N. arthritidis & IFM 10035 \\
\hline & N. asiatica & IFM 0245 \\
\hline & N. exalbida & IFM 0803 \\
\hline & N. pneumoniae & IFM 0784 \\
\hline \multirow[t]{5}{*}{3} & N. alba & IFM 10588 \\
\hline & N. cummidelens & IFM 10176 \\
\hline & N. fluminea & IFM 10138 \\
\hline & N. salmonicida & IFM 0849 \\
\hline & N. soli & IFM 10177 \\
\hline \multirow[t]{2}{*}{4} & N. anaemiae & IFM 0323 \\
\hline & N. vinacea & IFM 10175 \\
\hline \multirow[t]{2}{*}{5} & N. araoensis & IFM 0575 \\
\hline & N. beijingensis & IFM 10174 \\
\hline \multirow[t]{3}{*}{6} & N. asteroides & IFM 0319 \\
\hline & N. neocaledoniensis & IFM 10560 \\
\hline & N. thailandica & IFM 10145 \\
\hline \multirow[t]{2}{*}{7} & N. caishijiensis & IFM 10344 \\
\hline & N. ignorata & IFM 10475 \\
\hline \multirow[t]{2}{*}{8} & N. carnea & IFM 0237 \\
\hline & N. flavourosea & IFM 0851 \\
\hline \multirow[t]{2}{*}{9} & $N$. concava & IFM 0354 \\
\hline & N. seriolae & IFM 0286 \\
\hline \multirow[t]{2}{*}{10} & N. higoensis & IFM 10084 \\
\hline & N. shimofusensis & IFM 10331 \\
\hline \multirow[t]{2}{*}{11} & N. inohanensis & IFM 0092 \\
\hline & N. yamanashiensis & IFM 0265 \\
\hline \multirow[t]{2}{*}{12} & N. miyunensis & IFM 10632 \\
\hline & N. vaccinii & IFM 10284 \\
\hline \multirow[t]{2}{*}{13} & N. sienata & IFM 10088 \\
\hline & N. testacea & IFM 0937 \\
\hline 14 & N. brasiliensis & IFM 0236 \\
\hline 15 & N. brevicatena & IFM 0283 \\
\hline 16 & N. crassostreae & IFM 10173 \\
\hline 17 & N. cyriacigeorgica & IFM 10235 \\
\hline 18 & N. farcinica & IFM 0284 \\
\hline 19 & N. jiangxiensis & IFM 10633 \\
\hline 20 & N. niigatensis & IFM 0833 \\
\hline 21 & N. otitidiscaviarum & IFM 0239 \\
\hline 22 & N. paucivorans & IFM 10001 \\
\hline 23 & $N$. pigrifrangens & IFM 10533 \\
\hline 24 & N. pseudobrasiliensis & IFM 0624 \\
\hline 25 & N. pseudovaccinii & IFM 10376 \\
\hline 26 & N. puris & IFM 10564 \\
\hline 27 & N. takedensis & IFM 10572 \\
\hline 28 & N. transvalensis & IFM 0333 \\
\hline
\end{tabular}




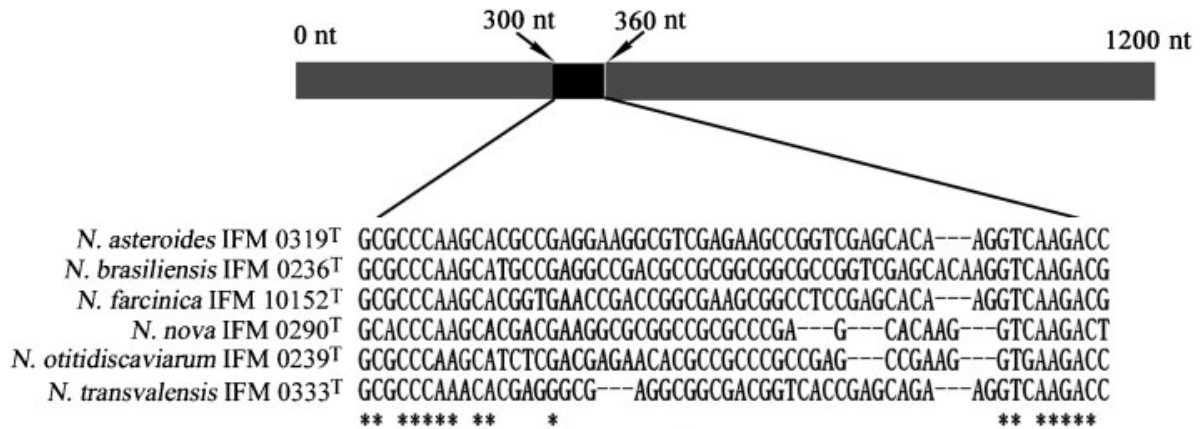

Fig. 2. Signature base sequence motif of the gyrB gene for discrimination of clinically important Nocardia species: $N$. asteroides, Nocardia brasiliensis, N. farcinica, N. nova, Nocardia otitidiscaviarum and Nocardia transvalensis. Asterisks indicate identical nucleotides, and dashes indicate nucleotides not present in the sequence.

growth characteristics at $45{ }^{\circ} \mathrm{C}$ (Conville et al., 2004; Kageyama et al., 2004c).

In contrast, although a minimal difference (similarity of $99.5 \%$ ) in the 16S rRNA gene sequences has been found between Nocardia paucivorans and Nocardia brevicatena (Roth et al., 2003), they could clearly be differentiated from each other by gyrB gene analysis, with a similarity of $92.8 \%$ in this study. Other closely related species such as $N$. carnea and $N$. flavorosea, with a high $16 \mathrm{~S}$ rRNA gene similarity of 99.3\% (Roth et al., 2003), could also be distinguished by gyrB sequence, with $93.7 \%$ sequence similarity (79 nt difference), indicating the usefulness of sequence analysis of $g y r B$ genes in the classification.

N. exalbida was grouped into cluster 2 (with N. abscessus, $N$. arthritidis, $N$. asiatica, $N$. pneumoniae) based on gyrB analysis (Table 4, Fig. 1b), although it was grouped with Nocardia xishanensis based on 16S rRNA gene analysis (with a similarity of $98.7 \%$; Fig. 1a). Both N. miyunensis and N. vaccinii were grouped into cluster 12 by gyrB gene sequences (with a similarity of $94.7 \%$; Table 4, Fig. 1b), but the two species were separated into different clusters in the phylogenetic analysis of the $16 \mathrm{~S}$ rRNA gene (with a similarity of $97.2 \%$; Fig. 1a). These data showed that some discrepancies exist in the phylogenetic positions of the species based on gyrB or $16 \mathrm{~S}$ rRNA gene sequences. Therefore, genetic analyses based on other genes might be helpful for establishing a robust taxonomic relationship for Nocardia species. The introduction of comprehensive multilocus strain typing methods might be helpful (Hanafy et al., 2008).

Within the gyrB nucleotide sequences of approximately $1200 \mathrm{nt}$ analysed in the present study, we found a speciesspecific region of $60 \mathrm{nt}$, starting at approximately $300 \mathrm{nt}$ from the initiation codon (Fig. 2). The sequence information from this region of the gyrB gene might help in the design of useful PCR primers for the rapid identification of pathogenic Nocardia species in clinical laboratories.

The introduction of new molecular methods has had an enormous impact on the taxonomy of actinomycetes including members of the genus Nocardia (Kang et al., 2009). Information from $16 \mathrm{~S}$ rRNA gene sequences has been used regularly for these studies (Brown-Elliott et al., 2006). However, the divergence of $16 \mathrm{~S}$ rRNA gene sequences within Nocardia species is too low to satisfy taxonomic analyses. This study therefore shows the usefulness and limits of $\operatorname{gyr} B$ gene sequencing for phylogenetic studies and species identification for members of the genus Nocardia.

\section{ACKNOWLEDGEMENTS}

This work was supported by a Grant-in-Aid for Scientific Research (C) and Special Coordination Funds for Promoting Science and Technology from the Ministry of Education, Culture, Sports, Science and Technology of Japan, and the International Science \& Technology Cooperation Plan of Guizhou Province [qian-ke-he-wai-G-zi (2009) 700114], PR China. Nocardia strains were obtained through the National BioResource Project (NBRP) in Japan (http:/www.nbrp.jp/).

\section{REFERENCES}

Brown-Elliott, B. A., Brown, J. M., Conville, P. S. \& Wallace, R. J., Jr (2006). Clinical and laboratory features of the Nocardia spp. based on current molecular taxonomy. Clin Microbiol Rev 19, 259-282.

Chun, J. \& Goodfellow, M. (1995). A phylogenetic analysis of the genus Nocardia with $16 \mathrm{~S}$ rRNA gene sequences. Int J Syst Bacteriol 45, 240-245.

Conville, P. S., Brown, J. M., Steigerwalt, A. G., Lee, J. W., Anderson, V. L., Fishbain, J. T., Holland, S. M. \& Witebsky, F. G. (2004). Nocardia kruczakiae sp. nov., a pathogen in immunocompromised patients and a member of the "N. nova complex". J Clin Microbiol 42, 5139-5145.

Goodfellow, M. (1998). Nocardia and related genera. In Topley and Wilson's Microbiology and Microbial Infections, 9th edn, vol. 2, Systematic Bacteriology, pp. 463-489. Edited by A. Balows \& B. I. Duerden. London: Edward L. Arnold.

Hanafy, A., Kaocharoen, S., Jover-Botella, A., Katsu, M., lida, S., Kogure, T., Gonoi, T., Mikami, Y. \& Meyer, W. (2008). Multilocus microsatellite typing for Cryptococcus neoformans var. grubii. Med Mycol 46, 685-696.

Hoshino, Y., Watanabe, K., lida, S., Suzuki, S., Kudo, T., Kogure, T., Yazawa, K., Ishikawa, J., Kroppenstedt, R. M. \& Mikami, Y. (2007). 
Nocardia terpenica sp. nov., isolated from Japanese patients with nocardiosis. Int J Syst Evol Microbiol 57, 1456-1460.

Ishikawa, J., Yamashita, A., Mikami, Y., Hoshino, Y., Kurita, H., Hotta, K., Shiba, T. \& Hattori, M. (2004). The complete genomic sequence of Nocardia farcinica IFM 10152. Proc Natl Acad Sci U S A 101, 14925-14930.

Kageyama, A., Torikoe, K., Iwamoto, M., Masuyama, J., Shibuya, Y., Okazaki, H., Yazawa, K., Minota, S., Kroppenstedt, R. M. \& Mikami, Y. (2004a). Nocardia arthritidis sp. nov., a new pathogen isolated from a patient with rheumatoid arthritis in Japan. J Clin Microbiol 42, 23662371.

Kageyama, A., Poonwan, N., Yazawa, K., Mikami, Y. \& Nishimura, K. (2004b). Nocardia asiatica sp. nov., isolated from patients with nocardiosis in Japan and clinical specimens from Thailand. Int J Syst Evol Microbiol 54, 125-130.

Kageyama, A., Suzuki, S., Yazawa, K., Nishimura, K., Kroppenstedt, R. M. \& Mikami, Y. (2004c). Nocardia aobensis sp. nov., isolated from patients in Japan. Microbiol Immunol 48, 817-822.

Kageyama, A., Yazawa, K., Mukai, A., Kohara, T., Nishimura, K., Kroppenstedt, R. M. \& Mikami, Y. (2004d). Nocardia araoensis sp. nov. and Nocardia pneumoniae sp. nov., isolated from patients in Japan. Int J Syst Evol Microbiol 54, 2025-2029.

Kageyama, A., Yazawa, K., Nishimura, K. \& Mikami, Y. (2005). Nocardia anaemiae sp. nov. isolated from an immunocompromised patient and the first isolation report of Nocardia vinacea from humans. Nippon Ishinkin Gakkai Zasshi 46, 21-26.

Kang, Y., Takeda, K., Yazawa, K. \& Mikami, Y. (2009). Phylogenetic studies of Gordonia species based on gyrB and secAl gene analyses. Mycopathologia 167, 95-105.

Kimura, M. (1980). A simple method for estimating evolutionary rates of base substitutions through comparative studies of nucleotide sequences. J Mol Evol 16, 111-120.
Maldonado, L., Hookey, J. V., Ward, A. C. \& Goodfellow, M. (2000). The Nocardia salmonicida clade, including descriptions of Nocardia cummidelens sp. nov., Nocardia fluminea sp. nov. and Nocardia soli sp. nov. Antonie Van Leeuwenhoek 78, 367-377.

McMinn, E. J., Alderson, G., Dodson, H. I., Goodfellow, M. \& Ward, A. C. (2000). Genomic and phenomic differentiation of Rhodococcus equi and related strains. Antonie Van Leeuwenhoek 78, 331-340.

Poonwan, N., Mekha, N., Yazawa, K., Thunyaharn, S., Yamanaka, A. \& Mikami, Y. (2005). Characterization of clinical isolates of pathogenic Nocardia strains and related actinomycetes in Thailand from 1996 to 2003. Mycopathologia 159, 361-368.

Roth, A., Andrees, S., Kroppenstedt, R. M., Harmsen, D. \& Mauch, H. (2003). Phylogeny of the genus Nocardia based on reassessed $16 \mathrm{~S}$ rRNA gene sequences reveals underspeciation and division of strains classified as Nocardia asteroides into three established species and two unnamed taxons. J Clin Microbiol 41, 851-856.

Saitou, N. \& Nei, M. (1987). The neighbor-joining method: a new method for reconstructing phylogenetic trees. Mol Biol Evol 4, 406425.

Stackebrandt, E., Rainey, F. A. \& Ward-Rainey, N. L. (1997). Proposal for a new hierarchic classification system, Actinobacteria classis nov. Int J Syst Bacteriol 47, 479-491.

Thompson, J. D., Higgins, D. G. \& Gibson, T. J. (1994). CLUSTAL W: improving the sensitivity of progressive multiple sequence alignment through sequence weighting, position-specific gap penalties and weight matrix choice. Nucleic Acids Res 22, 4673-4680.

Yamamoto, S. \& Harayama, S. (1995). PCR amplification and direct sequencing of $g y r B$ genes with universal primers and their application to the detection and taxonomic analysis of Pseudomonas putida strains. Appl Environ Microbiol 61, 1104-1109.

Yazawa, K., Mikami, Y., Maeda, A., Akao, M., Morisaki, N. \& Iwasaki, S. (1993). Inactivation of rifampicin by Nocardia brasiliensis. Antimicrob Agents Chemother 37, 1313-1317. 